\title{
Cognitive Modeling of Management Strategies of the Enterprises: The Experience of Developing and Testing
}

\author{
Prof. Robert A. Karayev \\ Institute of Cybernetics of National Academy of Sciences, Baku, Azerbaijan \\ karayevr@rambler.ru \\ Islam I. Safarly \\ SAFTEX Ltd. Co, Managing Director, Baku, Azerbaijan
}

Teymur F. Abduragimov

Azerbaijan Global İnvestment, Executive Director, Baku, Azerbaijan

Kamran A. Aliyev

British Petroleum, GPO SCPX Project

\begin{abstract}
The paper discusses the difficulties of choice strategies of enterprises development in modern complicated turbulent environments. Ill-structured (by G. Simon ) and the dynamic nature of the problem of choice restricts the opportunities to use traditional widely known DSS-tools (SWOT \& PEST, BSC, CCB, SODA, SAM, SAST, SCA, BCG, GE / McKinsey, Shell / DPM, MD ASQ et al.). New prospects for solution of the issue open ideas and methods such us "cognitive modelling" which today is major component of the global trend of world science - «NBIC Convergence". Some progress in terms of development and use of cognitive DSS-tools of strategic management was achieved over the past two decades. However it becomes apparent (and some "bottlenecks" are caused by complex phenomenology of modern management), that it is difficult to formalize. The paper presents the methodology of cognitive modeling and cognitive DSS-tools oriented to allow deal with this kind of "bottlenecks". The purpose of the article: a) present the short overview of the main provisions and basic tools of the developed methodology, and b) present the main results obtained in process of development and testing research prototypes of cognitive models for three companies with different structure and dynamics of their macroeconomic environment.
\end{abstract}

Keywords: enterprise strategy, dynamic analysis, cognitive approaches, cognitive models.

\section{INTRODUCTION}

The task of choosing strategies faced by the managers of enterprises in today's turbulent business environment can be fully attributed to the tasks of management of ill-structured problem situations [1], i.e. to problems not amenable to exact formally mathematical analysis. In recent years as promising support tools for solving this kind of tasks are considered the cognitive models $[2,3,4,5,6,7$, and 8]. The article contains the results of the development and testing of cognitive models to assess strategic perspectives of three concrete enterprises that are significantly different in structure and dynamics of macroeconomic environment and internal microeconomic conditions. 
This projects is not intended to create working models. Developments used of research character and were performed by three independent groups as bellows:

$\circ$ A general description of the cognitive modeling of management strategies, reflecting the features of the economic management in an uncertain economic environment;

- A conceptual scheme of the task from the standpoint of "model theory" solvers illstructured problems;

- Brief description of cognitive models of the strategies established as part of the executed projects;

- Some of the most important, in our view, the results which, although correlated with the features of specific enterprises, may be of interest to developers of strategies for other enterprises.

Conclusions presented in the final part, reflect not only the opinion of model developers, but also the opinion of employees of enterprises.

\section{Common Characteristics}

\section{COGNITIVE APPROACH}

Cognitive approach is a method of studying and managing problem situations basing on formation and study of their cognitive models $[2,5,7,9$, and 10$]$.

Cognitive model is complex, and includes

- Cognitive map of a problem situation, reflecting the mental models of experts regarding the structural and functional organization of this situation;

- Methods of analysis of cognitive map, allowing to investigate the structural properties of the problem situation and carry out model experiments in order to search the optimal (in some sense or other) management strategies for problem situation

Cognitive revolution happened in 1950-1960s. The first cognitive research center was established in Harvard in 1960. This date is indicated as the development of cognitive science, which includes philosophy, cognitive psychology, neurophysiology, anthropology, linguistics and theory of artificial intelligence.

Methodology of cognitive modeling is addressed for analysis and decision-making in complex ill-structured situations. The first applied versions of this methodology were suggested by R. Axelrod [11]. Modern trend of the cognitive approach are well reflected at Proceedings of the International Conferences of ICCM series [12].

A specific feature of the cognitive modeling method differing it from traditional methods is the possibility of conducting multi-factor and multi-criteria analysis and management of development of ill-structured situations (combining vitally important stages of divergence, convergence and transformation of project cycle [13]) that is not possible through traditional mathematical and statistical calculus's.

\section{Cognitive map}

Cognitive map is a structure (network) of cause and effect relations between the components of the system under survey and its surrounding environment, reflecting the explicit understanding (mental models) of expert(s) about the structure and functioning of this system $[7,14]$. In the context of control problems the ontologies of cognitive map are:

- Basic factors (concepts) characterizing the control object and its environment according to the representation of subject of control

- As well as cause and effect relations between basic factors. 
Such a factor division lets realize wide range of model experiments, for instance, construction of different alternative strategy versions, to prognoses the utility's behavior (its goal form) for every strategy version, to prognoses the utility's behavior in various dynamics of external environment factors and etc.

\section{Methods of analysis of cognitive maps}

Methods of analysis of cognitive maps are the sets of methods which allow various kinds of model experiments on cognitive maps, associated with studies and virtual management of problem situation. Efforts of scientists are currently focused on the development of methods of analysis, that allow:

- To investigate the most important structural properties of the problem situations (consistency of target factors, priority of control actions, dynamic stability of management strategies, etc.);

- Predict the development of the problem situation under various management strategies (self-development, controlled development) and under various scenarios of environmental change.

Cognitive modeling is a periodic process and consists of several interrelated stages main of which are: cognitive structuring and development of cognitive map of surveyed situation; structural analysis of cognitive map; scenario based modeling of development of situation (self-development and controlled development).

\section{Stages of cognitive modeling \\ Cognitive structuring}

Stage provides for the definition of the factors that characterize the internal situation at the enterprise and PEST- factors of environment influencing the enterprise development.

The cognitive structuring stage is formed as a cognitive map (CM) describing a set of basic factors of the enterprise and its environment and cause and effect relations between them. Currently common feature for all researches on cognitive modeling is the use of cognitive maps based on the digraph (signed or weighed) [15].

For each factor its value (or tendency of change) characterizing the subject, event or process associated with the given factor is determined. For cause and effect relations character and strength of interrelation between basic factors is determined. Values of appropriate variable are given on the basis of a linguistic scale, i.e. in words in a native language and each is denoted by a corresponding figure in the interval $[0 ; 1]$. Example of a cognitive map of the strategic management of the enterprise is given in [16].

Ibid is given an example of linguistic scale.

In this stage the basis of set the basic factors also are determined: subset of target factors and subset of controlled factors, also, initial values and/or tendencies of change of basic factors. Factors relating to the enterprise or to external environment, which the management of the enterprise may influence on, are selected as controlled factors.

\section{Structural analysis of cognitive map}

This analysis is implemented to study structural features of CM which are important from the point of view of management practice. Such features include:

- Non-conflicting purposes. The main point of the non-conflicting purposes vector is to ensure that desired change of some target factors does not result in undesirable change of others. 
- Non-conflicting purposes and controlled factors. Managing the situation is the change of controlled factors to the extent that would result in desired change of target factors, i.e. in the direction of planned dynamics. In connection with this, effectiveness of influence of controlled factors on targets of the company and conformity of controlled factors with the targets of the company are surveyed. Acceptable effectiveness of controlled factors is determined by the degree and character of their influence on the target factors. Conformity of controlled factors with targets vector means that no change of them should cause change in any of the targets in undesired direction.

At present a range of mathematical methods of structural analysis of CM has been developed $[10,15]$. However, in practice, structural solutions achieved through these formal and mathematical methods require interpretations in the subject area, which are not always possible.

\section{Scenario based modeling of situation development}

This is conducted for comparative analysis of the trajectories of the situation development in different incoming managing impacts and different scenarios changes of environment. Modeling may be conducted in a mode of self-development and in a mode of manageable development. In the most studies the dynamics of development is modeled using the apparatus of linear dynamical systems [15].

Self-development implies maintaining existing tendencies of factors and in essence, it is extrapolation of current situation taking into account mutual influences of basic factors. Managed development of situation implies purpose targeted influence on one or several managed factors. Impulsive change of current value of the factor which is transferred to other factors through the chains of impacts serves as management.

Modern concepts of cognitive approach to the management of enterprise (purposes and crucial definitions, CM structuring principles and adequacy criteria, types of CM and their analysis methods) are described in [2, 6, 10, and 12]. In the framework of these concepts cognitive strategy modeling is strategy modeling based on cognitive maps (CM), which search for optimal (in one sense or another) strategies of enterprise development.

Systemization of CM and their analysis methods are given in [10,15, 17, 18, and 19]. Systemization of principles and methods of reliability assessment of CM, which allows to block typical errors of explication of expert knowledge and to raise adequacy of CM are given in [20, 21]. Depending on conditions and limitations of strategy development task the appropriate CM types and their analysis methods can be chosen.

\section{A COGNITIVE METHODOLOGY FOR DEVELOPING OF ENTERPRISE STRATEGY Enterprise strategy}

To the question posed by M. Porter, "What is strategy?" [22], currently, there are many answers. Many different definitions of "enterprise strategy" have been proposed [23]. Analysis of these definitions shows that in the most general form "enterprise strategy" may be interpreted as follows.

Enterprise strategy is a general plan of action that defines the priorities of strategic objectives, resources and sequence of steps to achieve strategic objectives. The main objective of the strategy is to move the enterprise from its current state to a desired future state [24]. The task of search an optimal strategy in today's turbulent economy is extremely complex. It can be fully attributed to the class of ill-structured problems [1], the solution of which is located outside the traditional theory of strategic management of enterprises. Solution of such 
problems requires fundamentally new approaches and new support tools. One of the most promising approaches is based on the ideas and methods of the cognitive paradigm.

Among the first attempts to use cognitive technology to solve tasks of strategic management is referred SODA methodology [13]. According to the authors of SODA, the methodology is general and can be used to study complex situations in a variety of problem areas. Unfortunately, the phenomenology of the situation in each of the problem areas wears always specific character and requires the creation of their problem-oriented methodologies. In developing the problem-oriented methodology of cognitive support in the first place, it is important to establish a conceptual scheme of the task, which defines the statement of the task and task-solving scheme in representations of the cognitive approach.

\section{Conceptual scheme of strategy development task}

Conceptual scheme of general task of the ill-structured objects management was offered by acad. D. A. Pospelov [25]. Strategy development task is a particular case of general task and in terms of cognitive approach it can be presented as follows:

$$
P(G, M): S^{0} \underset{U(P)}{\longrightarrow} S^{c},
$$

Where $P(G, M)$ - is full knowledge of task;

$\mathrm{G}$ - cognitive map of the task;

M - methodology of support, which bases on the modern postulates of strategy management and includes methods of choice of business-conception of enterprise $\left(\mathrm{M}_{\mathrm{b}}\right)$, methods for design of cognitive map $\left(M_{d}\right)$, methods for analysis of cognitive map $\left(M_{a}\right)$; $\mathrm{S}^{\mathrm{o}}$ - the current state of enterprise, installed via cognitive map;

$\mathrm{S}^{\mathrm{c}}$ - the goal state of enterprise, installed via cognitive map;

$\mathrm{U}(\mathrm{P})$ - optimal (in one sense or another) strategy that determine strategic steps sequence, leading from $S^{o}$ to $S^{c}$.

Depending on the character of macroeconomic environment (stable/unstable) two task versions are possible: static and dynamical. In static version the search of effective strategy is to choice one strategic step leading from $S^{\text {o }}$ to $S^{c}$. In dynamical version the search of effective strategy is to choice of strategic steps sequence leading from $S^{\circ}$ to $S^{c}$.

This and other methods of analysis are used: "method of searching priority impacts", "method of scenario-based analysis of the dynamics of the situation", "method of analysis of dynamic stability of strategy" and others.

Leading method to search optimal strategies in turbulent environment is the scenario-based method of dynamic analysis of a problem situation. This method allows to searching the target situation on the set of alternative strategies for various environment development scenarios. The mechanism of scenario-based dynamic analysis was developed by us [26, 27, and 28] and is different from the classical cognitive model of linear dynamical systems [15].

Applied versions of dynamic analysis models, especially dynamic analysis models of enterprise's strategy require the adjustment of the "strategic step" definition. Each of strategic steps is action which changes the situation. The changes on each step can be realized by operators, which are described in the Table 1. Here the list of operators is divided into signed cognitive map (SCM) and weighted cognitive map (WCM). 
Table 1: Operators of Strategic Step

\begin{tabular}{|l|c|c|}
\hline \multicolumn{1}{|c|}{ Operators } & \multicolumn{2}{c|}{ Types of CM } \\
\cline { 2 - 3 } & WCM & SCM \\
\hline 1. Change the values of some managed vertices (factors) at a certain time & $\bullet$ & $\bullet$ \\
\hline 2. Add a new vertex (factor) and the new arcs to it and from it at certain time & $\bullet$ & $\bullet$ \\
\hline 3. Change sign of some arc at a certain time & $\bullet$ & $\bullet$ \\
\hline 4. Change weight of some arc at a certain time & $\bullet$ & \\
\hline 5. Add an arc between existing vertices (factors) at a certain time & $\bullet$ \\
\hline 6. Add a new contour (which increases or decreases deviation) at a certain time & $\bullet$ \\
\hline
\end{tabular}

The use these management operators can construct numerous strategic alternatives, which reflect various scenarios of situation development. As soon as the fixed set of strategic alternatives is determined, you can define the statement of strategy selection task. It may have different formulations and configurations of target form of problem situation. For example,

- Searching optimal strategy (the shortest, the cheapest and etc.) which meets normative restrictions in some parameters of utility's internal and external environment;

- Searching a strategy, which maximizes (minimizes) the values of some tops (for instance, profit of enterprises, market share of enterprises, product quality, pollution of environment and etc.) in case of restrictions in values of some other tops (for instance, financial resources, time resources, human resources, and etc.);

- Searching a strategy, which doesn't let every variable of enterprise have excessively large or excessively little value (it is called "dynamically stable" strategies).

Designed mechanism of scenario-based dynamic analysis is based on the

○ "General theory of impulse processes" on digraphs (signed and weighted) [15],

- Theoretical model of non-linear (non-monotonic) dynamical systems [29],

- Algorithms of strategic planning of knowledge-based solvers by the "direct wave" and by "reverse wave" [25, 29],

○ Principles and methods of scenario planning [30, 31, 32, 33, 34].

The mechanism of this type removes many limitations of theoretical schemes and approximates the management practices to the leading postulates of modern pragmatic management (of 21- th Century):

Postulate 1. The management from the future [35];

Postulate 2. Knowledge-based processing of uncertainty [14, 36, 37, and 38];

Postulate 3. The requisite of variety of control mechanism [39];

Postulate 4. Strategy is general path rather than precise steps $[24,25$, and 40$]$.

Postulate 5. Hierarchical modeling (planning) strategies under various PEST-scenarios of development of the environment (pessimistic scenario, inertial, optimistic)

Process of constructing strategy is iterative and ends when reaching a satisfactory result, which is under defined restrictions, managed to achieve target state of a problem situation.

\section{EXAMPLES OF COGNITIVE STRATEGY MODELING}

The attempts of cognitive modeling which we did make were concerned with the solution of management tasks in three research projects:

Project 1. Strategy perspective assessment of offshore-oil Company, functioning conditions which are characterized with typical current tendencies: downturn of world oil prices, global financial crisis, increase of governmental impact, toughening of ecological standards. The work 
was implemented together with Petroleum Engineering Department of A\&M Texas University (College Station, Texas, USA) in the framework of constructive cooperation agreement.

Project 2. Exposure of crucial competences for strategic development task of telecommunication companies, which deal with development, installation and service of industrial, administrative and medical information systems, iP-and CTi- systems - telephoning for communication statement and corporative clients.

Project 3. Analysis of management efficiency in poultry enterprise of one of the holdings. The task was specified by critical situation, which occurred due to the increase of raw materials and feed prices, decrease of finished product prices, the raise of competitive pressure, the difficulties in obtaining commercial credits, lack of qualification of managerial staff, drop of income share, which is considered for refinancing the enterprises (especially because of corruptibility of controlling units and etc.).

Now let's learn brief characteristics of developed cognitive models for above mentioned projects. The main characteristics of developed cognitive models are: business-concept of strategy, defined due to the results of strategic diagnosis of enterprises; structure type of cognitive map, which describes the logic of business-concept; methods of design and analysis of cognitive map; the scale of values and pace of change of factors of cognitive map. Characteristics of cognitive models, which were developed in the mentioned projects, are described in the Table 2.

Table 2: Characteristics of Cognitive Models, developed in Projects 1, 2, 3

\begin{tabular}{|c|c|c|c|c|}
\hline $\begin{array}{l}\text { Project } \\
\text { number }\end{array}$ & $\begin{array}{l}\text { Business- } \\
\text { concept }\end{array}$ & $\begin{array}{l}\text { Structural } \\
\text { type of } \\
\text { cognitive } \\
\text { map }\end{array}$ & $\begin{array}{l}\text { Methods of design and analysis of } \\
\text { cognitive maps }\end{array}$ & $\begin{array}{l}\text { Scales for } \\
\text { estimating the } \\
\text { values of factors } \\
\text { and its trends }\end{array}$ \\
\hline Project No 1 & $\begin{array}{l}\text { "Resource- } \\
\text { oriented» [41] }\end{array}$ & $\begin{array}{c}\text { Weighted } \\
\text { digraphs } \\
{[15]}\end{array}$ & $\begin{array}{l}\text { Methods of design: } \\
\text { SWOT \& PEST-analysis, Determinacy } \\
\text { analysis [42], Implicational repertory } \\
\text { grids of the C. Hinkle [43], Matrix } \\
\text { interactions [13], Methods of } \\
\text { experimental psychosemantics and } \\
\text { nonmetric multidimensional scaling [44, } \\
45] \text {. } \\
\text { Methods of analysis: } \\
\text { Models of linear dynamics of the F. } \\
\text { Roberts [15], Methods of scenario } \\
\text { planning [26, 27, 32]. }\end{array}$ & $\begin{array}{l}\text { Bipolar linguistic } \\
\text { Five-point rating } \\
\text { scale }\end{array}$ \\
\hline Project No 2 & $\begin{array}{c}\text { "School } \\
\text { competency" } \\
{[46]}\end{array}$ & $\begin{array}{c}\text { Matrix } \\
\text { Diagrams of } \\
\text { American } \\
\text { Society for } \\
\text { Quality [47] }\end{array}$ & $\begin{array}{l}\text { Methods of design: } \\
\text { Ishikawa diagrams [48], VRIO-analysis } \\
\text { [49], Reference model of business- } \\
\text { processes of the telecommunication } \\
\text { companies eTOM.4.0 (Enhanced } \\
\text { Telecom Operations Map), International } \\
\text { Telecommunication Union, "The model } \\
\text { of IS consumer opinion" (IBM, USA). } \\
\text { "Model of resources" (ASQ). } \\
\text { Methods of analysis: } \\
\text { Methods of matrix analysis [50]. } \\
\text { Analytic hierarchy model [51]. }\end{array}$ & $\begin{array}{l}\text { linguistic } \\
\text { Nine-point } \\
\text { rating scale }\end{array}$ \\
\hline
\end{tabular}




\begin{tabular}{|c|c|c|c|c|}
\hline Project No 3 & $\begin{array}{l}\text { "Migration } \\
\text { Strategy" [1] }\end{array}$ & $\begin{array}{c}\text { Weighted } \\
\text { digraphs } \\
{[15]}\end{array}$ & $\begin{array}{l}\text { Methods of design: } \\
\text { SWOT \& PEST-analysis. } \\
\text { The strategic map of the Kaplan-Norton } \\
\text { [52]. } \\
\text { Methods of experimental } \\
\text { psychosemantics and nonmetric } \\
\text { multidimensional scaling }[44,45] \text {. } \\
\text { Methods of analysis: } \\
\text { Model of scenario-based nonlinear } \\
\text { (non-monotonic) dynamics }[26,27,28] \text {. }\end{array}$ & $\begin{array}{l}\text { Bipolar linguistic } \\
\text { Five-point rating } \\
\text { scale }\end{array}$ \\
\hline
\end{tabular}

\section{CONCLUSION}

The experiments of cognitive strategy modeling and testing in the above-mentioned projects showed that in practical tasks of economic spheres cognitive modeling faces the same issues which the other intelligent technologies faces. These are "the width of problem definition", robustness when "paradigm shift", necessity of specialist-mediator (knowledge engineer, meta-interpreter - cognitivist), necessity of support tools on the development and maintenance stages and etc.

In general, the experiments of cognitive modeling and testing showed the following:

- In case of cognitive modeling of strategies the general principals of design of the cognitive map proposed in $[10,13]$ requires modification reflecting methodological features and concept determined by theory of strategic planning of enterprises.

- Cognitive modeling of strategies acquires a practical importance only in the framework of strategy planning methodology which includes phases of macro-economic and marketing analysis $[27,28]$. Ignoring these phases reduces cognitive models of strategies into mathematical objects which are far from reality of economic practice.

- The issue of choice of management scheme of problem solving caused wide discussion. At first, we applied the scheme proposed by specialists of Institute of Management Problems of RAS [10].

But analysis showed that proposed scheme implements algorithm of "situation-decision" type, i.e. implements not strategic, but reactive style of management and can't be used for generation of strategy in unstable environment. For such kind of problems are needed the schemes which implements algorithm of "situation-strategy-decision" type. Consequent researches showed that the issue of development of such scheme type is not trivial and it can be considered as one of directions for further improvement of cognitive approach.

- Cooperation with employees of the enterprises showed that they didn't have welldefined opinion regarding adequacy and efficiency of cognitive models of strategies. At the same time, 8 out of 11 demonstrated active interest and considered that cognitive modeling - is promising and useful technology. Our observations showed that the cognitive modeling is useful support tools, which stimulates cognitive and creative activity of strategy developers in most complicated phase of "strategic thinking" [24, 28, 53 - in phase with afferent synthesis of strategy.

- Set of methods directed to the increase of reliability of cognitive models on the stages of identification, conceptualization and CM-formalization of problematic knowledge $[2,3,5$, 
$17,18,19]$, can be extended at the expenses of including popular methods developed for analogous purposes in theory of industrial and architectural projecting [13], in experimental psychology [44, 45], and knowledge engineering [21].

- In all three projects, we faced with a situation that differs from the usual of theoretical schemes. Mental models of enterprises managers proved to be completely inadequate. It became clear that in the process of constructing cognitive maps of enterprises leading role should belong to the knowledge engineer (cognitivist) who owns the theoretical foundations of strategic planning and skills of cognitive modeling simultaneously.

- Experience working in three specific projects has shown that the problems with the choice of strategies here were due to the lack of strategic planning skills and difficulties of mental modeling of multifactor development of events in conditions of turbulent environment. This situation seems to us, is typical for most small and medium-sized enterprises. In this context, urgency of creation of cognitive support tools is no doubted. However, the effectiveness of these tools is still a big question. In each specific case serious work is needed to achieve sufficient adequacy of cognitive models, and character of this work is far from the populist estimates published in numerous recent works.

\section{References}

[1]. Simon, H. (1973.) The Structure of Ill-structured Problems. Artificial Intelligence, 4: pp. 181-202.

[2]. Eden, C. (1988). Cognitive Mapping: a Review. Eur. Journ. Oper. Res, 5(3): pp. 1-13.

[3]. Eden, C. (1992). On the Nature of Cognitive Maps. Journ. of Management Studies, 29(3): pp. 261-265.

[4]. Westcombe, M., Pidd, M., Mackenzie, A., Warren, I., \& Sommerville, S. (2002). Problem Solving Dialogue: Cognitive Mapping and IBIS. Working paper MS01/02. Management School, Lancaster University, UK. http://www.comp.lancs.ac.uk/computing/research/cseg/projects/wisdom/ (accessed 25.06.2014).

[5]. Huff, A. S. (1990). Mapping strategic thought. Chichester: Wiley.

[6]. Schellinck, J., \& Webster, R. (2013). Cognitive models: Understanding their critical role as explanatory and predictive hypothesis generators in cognition research. Proc. of the IEEE Intern. Conf. on Cognitive Modeling (ICCM-2013).

[7]. Russell, R.D. (1999). Developing a process model of entrepreneurial systems: a cognitive mapping approach. Entrepreneurship Theory and Practice, 23(3): pp. 65-85.

[8]. Hodqkinson, G. (2001). Cognitive process in strategic management: Some emerging trends and future directions. Handbook of industrial, work\&organizational psychology (pp. 416-441). London: SAGE Publication 2.

[9]. Eden, C. (1989). Using Cognitive Mapping for Strategic Options Development and Analysis. In: Rosenhead J.

(Ed.), Rational Analysis for a Problematic World (pp. 127-141). Chichester: Wiley.

[10].Proc. of the Intern. Conf. “Cognitive Analysis and Management of Development of Situations” (2007). CASC'2007. M.: Institute of Control Problems of RAS. http://window.edu.ru/resource/144/51144 (accessed 25.06.2014).

[11]. Axelrod, R. (1976). The Structure of Decision. In R. Axelrod (Ed.), Cognitive Maps of Political Elites (pp. $405-$ 427). Princeton: University Press.

[12]. IEEE Proc. of the Intern. Conf. on Cognitive Modeling (ICCM) series:

ICCM 2013: Ottawa, Canada (proceedings)

ICCM 2012: Berlin, Germany (proceedings)

ICCM 2010: Philadelphia, USA (proceedings)

ICCM 2009: Manchester, UK (proceedings) 
ICCM 2007: Ann Arbor, USA (proceedings)

ICCM 2006: Trieste, Italy (proceedings)

ICCM 2004: Pittsburgh, USA (proceedings)

ICCM 2003: Bamberg, Germany (proceedings)

ICCM 2001: Fairfax, USA (proceedings)

ICCM 2000: Groningen, Netherlands (proceedings)

ECCM 1998: Nottingham, UK (proceedings)

EuroCog 1996: Berlin, Germany (proceedings).

[13]. Jones, J. (1982). Design Methods. New York, Toronto, Chichester: John Wiley\&Sons.

[14]. Swan, J. (1995). Exploring knowledge and cognitions in decisions about technological innovation: mapping managerial cognitions. Human Relations, 48(11): pp. 1241-1270.

[15]. Roberts, F. (2011). Discreet mathematical models with application to social, biological and ecological issues. New Jersey: Prentice-Hall, Inc.

[16]. Karayev, R.A. (2014). Cognitive approach to the analysis and choice of innovation strategies of the enterprises. Journal of Investment and Management, 3(1): pp.1-6.

[17]. Westcombe, M. (2002). Problem structuring: the process of SODA modelling. Proc. of the ACM Hypertext Conference: Workshop on Facilitating Hypertext-Augmented Collaborative Modeling. University of Maryland, MD, USA.

[18]. Decision Explorer TM User's Guide, Version 3. (1997). Glasgow: Banxia Software Limited.

[19]. Decision ExplorerTM Reference Manual, Version 3.1. (2000). Glasgow: Banxia Software Limited.

[20]. Dorner, D. (1996). The Logic of Failure: Recognizing and Avoiding Error in Complex Situations. Basic Books Publ.

[21]. Waterman, D. (1986). Guide to Expert Systems. Addison-Wesley Publ.Co., Inc.

[22]. Porter, M. (1996). "What is Strategy?". Harvard Business Review, 7(3): pp. 42-57.

[23]. Nickols, By Ed. (2012). Strategy definitions and meaning. References on strategy.

http://www.nickols.us/strategy_definition.htm (accessed 25.06.2014)

Strategy (1967). B. H. Liddell Hart. Basic Books.

Strategic Planning (1979). George Steiner. Free Press.

The Rise and Fall of Strategic Planning (1994). Henry Mintzberg. Basic Books.

The Concept of Corporate Strategy, 2nd Edition (1980). Kenneth Andrews. Dow-Jones Irwin.

Competitive Strategy (1986). Michael Porter. Harvard Business School Press.

Top Management Strategy (1980). Benjamin Tregoe and John Zimmerman. Simon and Schuster.

Strategy: Pure and Simple (1993). Michel Robert. McGraw-Hill.

The Discipline of Market Leaders (1994). Michael Treacy and Fred Wiersema. Addison-Wesley.

"Customer Intimacy and Other Value Disciplines" (Jan-Feb 1993). Michael Treacy and Fred Wiersema. Harvard Business Review.

"The Span of Control" (May-June 1956). Lionel Urwick. Harvard Business Review.

[24]. Mintzberg, H. (1994). The Rise and Fall of Strategic Planning. N. Y.: Free Press.

[25]. Pospelov, D.A. (1986). Situational Management: Theory and Practice. Moscow: Nauka (in Russian) 
Karayev, R. A., Safarly, I. I., Abduragimov, T. F., \& Aliyev, K. A. (2014). Cognitive modeling of management strategies of the enterprises: The Experience of developing and Testing. Archives of Business Research, 2(4), 94-105

[26]. Karayev, R.A., Ismaylov, S. F., \& Sadhikova, N.Y. (2003). Models of scenario analysis. Trans. of the Nat. Acad. of Sci. of Azerbaijan. Series of phys.-math. and techn. sciences, XXIII(3): pp. 33-36 (in Russian).

[27]. Karayev, R.A. et al. (2004). Forming of corporate enterprise policies by means of fuzzy cognitive maps. Trans. of the Nat. Acad. of Sci. of Azerbaijan. Series of phys.-math. and techn. sciences, XXIII(2): pp. $37-54$ (in Russian). http://www.science.az/cyber/pdf/2004-2-24.pdf (accessed 25.06.2014).

[28]. Karayev, R. A., Safarli, I. I., Abdurahimov, T. F., \& Naghiyev, M. A. (2010). Cognitive analysis and company's innovative project management. Informative-management systems, 4(47): pp. 37-43 (in Russian).

[29]. Osipov, G.S. (1998). Dynamics in knowledge-based systems. Trans. of the Russian Academy of Sciences. Theory and system of management, 5: pp. 24-28 (in Russian).

[30]. Balston, B., \& Wilson, I. (2006). The Scenario Planning Handbook: Development strategies in uncertain times. Harlow: Pearson.

[31]. Lindgren, M. \& Bandhold, H. (2009). Scenario planning. The Link Between Future and Strategy. N. Y.: Palgrave MacMillan.

[32]. Nickols, F., \& Ledgerwood, R. (2005). The Goals Grid. A New Tool for Strategic Planning http://www.nickols.us/strategic_planning_tool.pdf (accessed 25.06.2014).

[33]. Ogilvy, J.A. (2002). Creating Better Futures: Scenario Planning as a Tool for a Better Tomorrow. Oxford University Press.

[34]. Michel, G. (2001). Creating Futures: Scenario Planning as a Strategic Management Tool. N.Y.: Economics.

[35]. Ansoff, I. (1965). Corporate Strategy: An Analytical Approach to Business Policy for Growth and Explanation. N. Y.: McGraw Hill.

[36]. Grant, R. (1996). Toward a knowledge-based theory of the firm. Strategic Management Journal, 17 (Winter special issue): pp. 109-122.

[37]. OECD Science, Technology and Industry Scoreboard 2011: Innovation and Growth in Knowledge. http://www.oecd.org/sti/oecdsciencetechnologyandindustryscoreboard2011innovationandgrowthinknowledge economies.htm (accessed 25.06.2014).

[38]. Holsapple, C., \& Whinston, A. (1996). Decision Support Systems: A Knowledge-based Approach. Minneapolis: West Publishing Co.

[39]. Ashby, W. (1956). An Introduction to Cybernetics. London: Chapman and Hall.

[40]. Makridakis, S. (1990). Forecasting, planning, and strategy for the 21st century. N. Y.: Free Press.

[41]. Grant, R.M. (1991). The resource-based theory of competitive advantage: implications for strategy formulation. California management review, 33(3): pp. 114-135.

[42]. Chesnokov, V.C. (1987). Determinacy Analysis. Moscow: Nauka (in Russian).

[43]. Fransella, F., \& Bannister, D. (1977). A manual for repertory grid technique. London: Academic Press.

[44]. Borg, I., \& Groenen, P. (2005). Modern Multidimensional Scaling: theory and applications (2nd Ed.). New York: Springer-Verlag.

[45]. Nonmetric Multidimensional Scaling Programs: by Mark Steyvers. http://www.granular.com/MDS/ (accessed 25.06.2014)

[46]. Prahalad, C. K., \& Hamel, G. (1990). The core competence of the corporation. Harvard business review, MayJune, pp.79-91.

[47]. Abbasov, A.M., Karayev, R. A., \& Safarli, I.I. (2006). Method identification of key management competencies telecommunications companies. Trans. of the Nat. Acad. of Sci. of Azerbaijan. Series of phys.-math. and techn. sciences, XXIII(3): pp. 15-20 (in Russian).

[48]. Statistic methods of quality improvement. (1990). In Hitosi Kume (Ed.) (translation from Japanese). Moscow: Nauka (in Russian). 
[49]. Barney, J. (1997). Looking inside for competitive advantage. In A. Campbell, K. Luchs (Ed.), Core competencybased strategy (pp. 13-29). London: Intern. Thomson Business Press.

[50]. Markus, M., \& Mink, H. (1972). The review under the theory of matrixes and matrix inequalities. M.: Nauka (in Russian).

[51]. Saaty, T. L. (1980). The analytic hierarchy process: Planning, priority setting, resource allocation. N.Y.: McGraw-Hill.

[52]. Kaplan, R. S. \& Norton, D. P. (1996). The Balanced Scorecard: Translating Strategy into Action. Harvard Business School Press.

[53]. Marakas, G. (1999). Decision Support Systems in the twenty-first century. New Jersey: Prentice-Hall, Inc. 